Supporting Information:

\title{
Recyclable and flexible polyester thermosets derived from microwave processed lignin
}

Yunsheng Xu, Karin Odelius and Minna Hakkarainen*

Department of Fibre and Polymer Technology, KTH Royal Institute of Technology, Teknikringen 56, 10044 Stockholm, Sweden.

Corresponding authors: minna@kth.se

This supporting information contains 7 figures and 1 table on 5 pages. 
TGA of lignin and lignin thermosets:
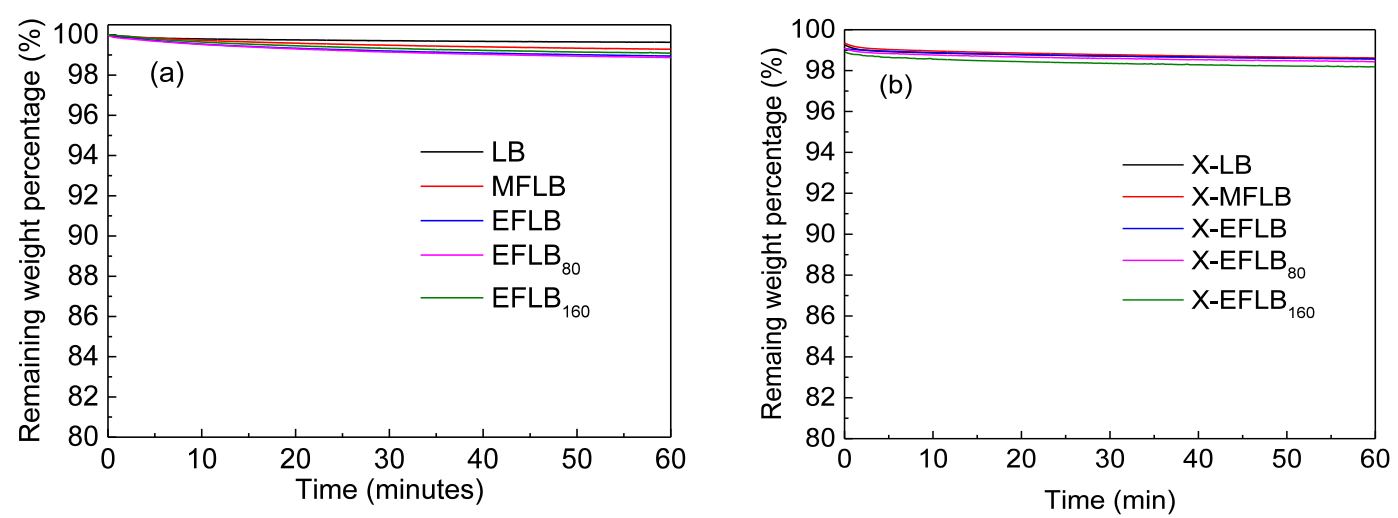

Figure S1. TGA curve of different lignin (a) and lignin thermoset (b) at $110^{\circ} \mathrm{C}$ for $1 \mathrm{~h}$.

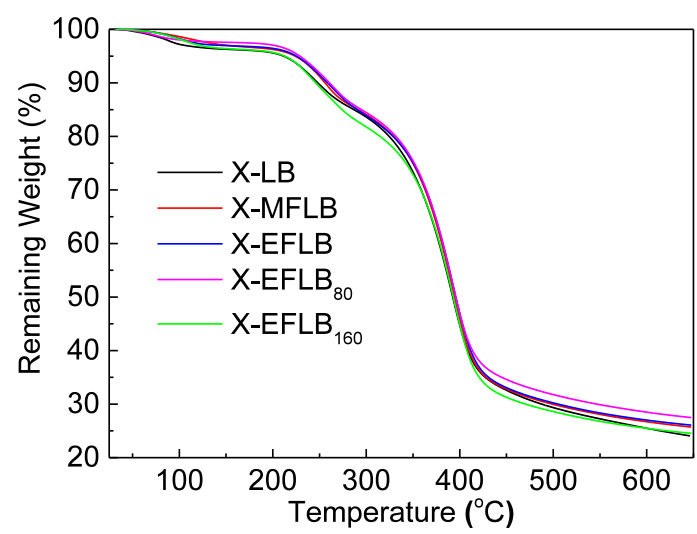

Figure S2. TGA curve of thermosets with different lignin types. 
The full FTIR spectrum of lignin thermoset:

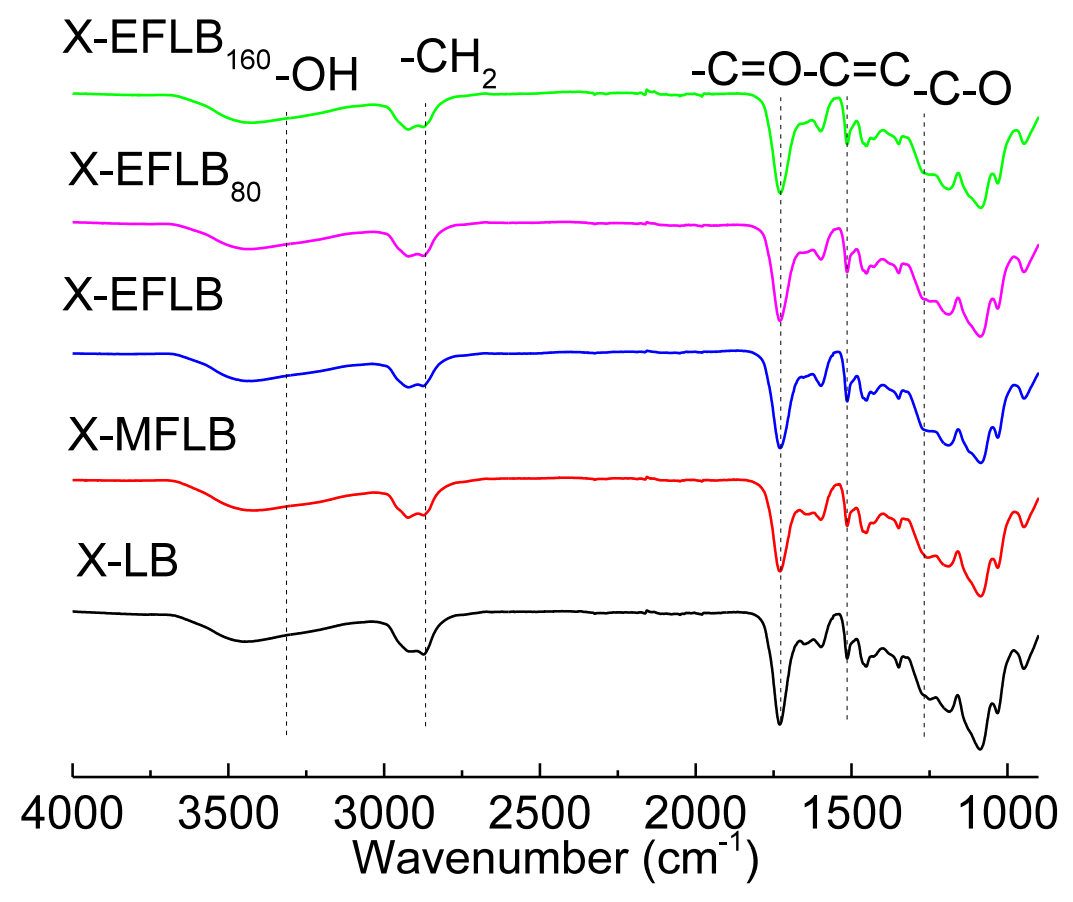

Figure S3. FTIR full spectrum of all lignin thermosets under transmission mode.

DSC of lignin thermosets:

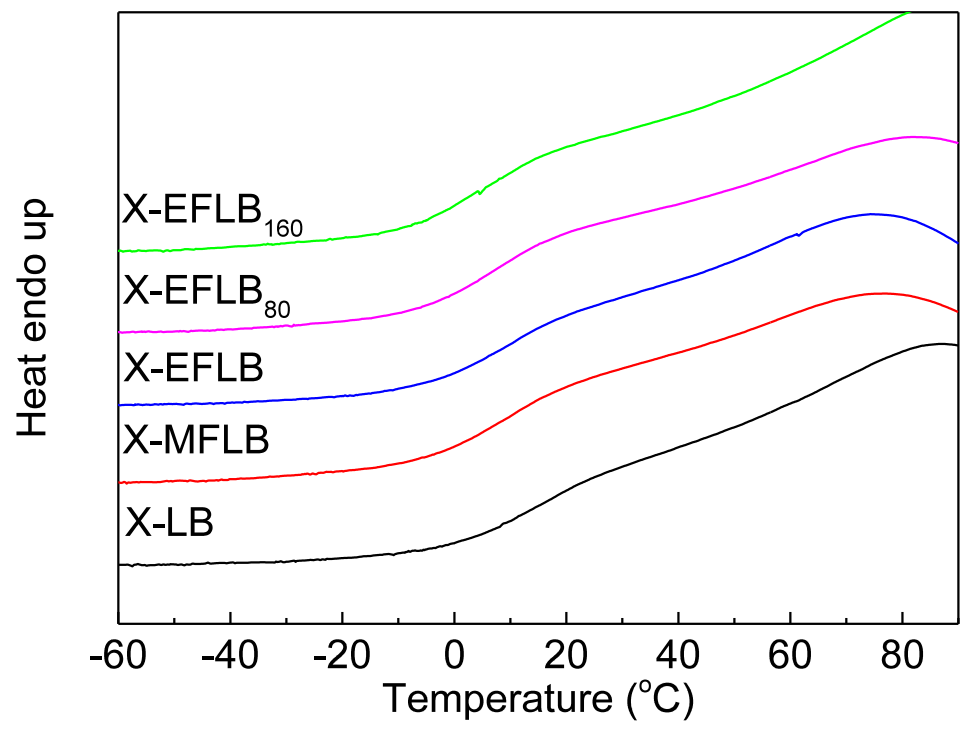

Figure S4. DSC curve of thermosets with different lignin types 
Microwave recycling and recuring of thermosets:

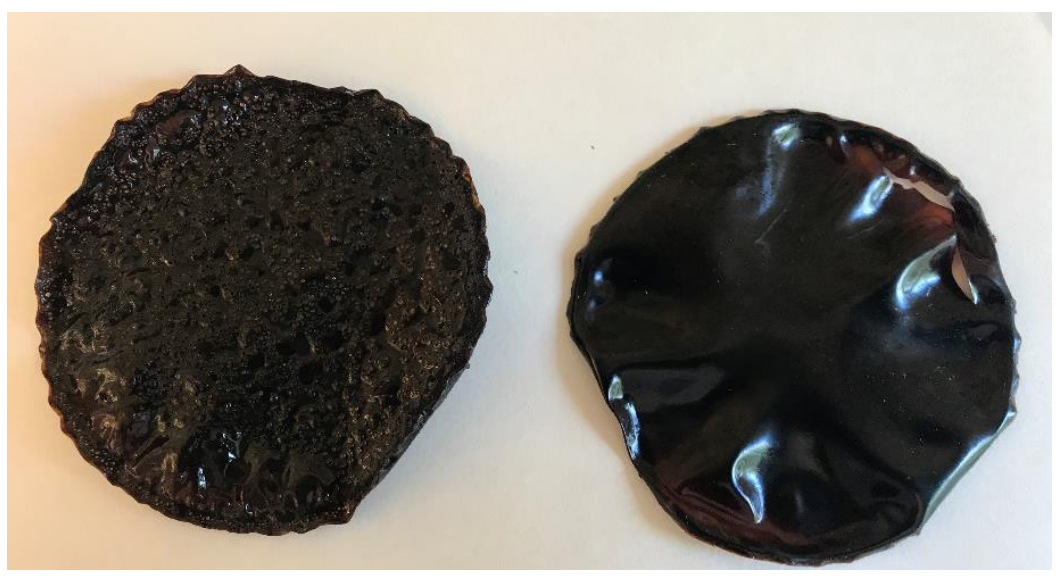

Figure S5. Digital picture of recycled X-LB and X-EFLB 160

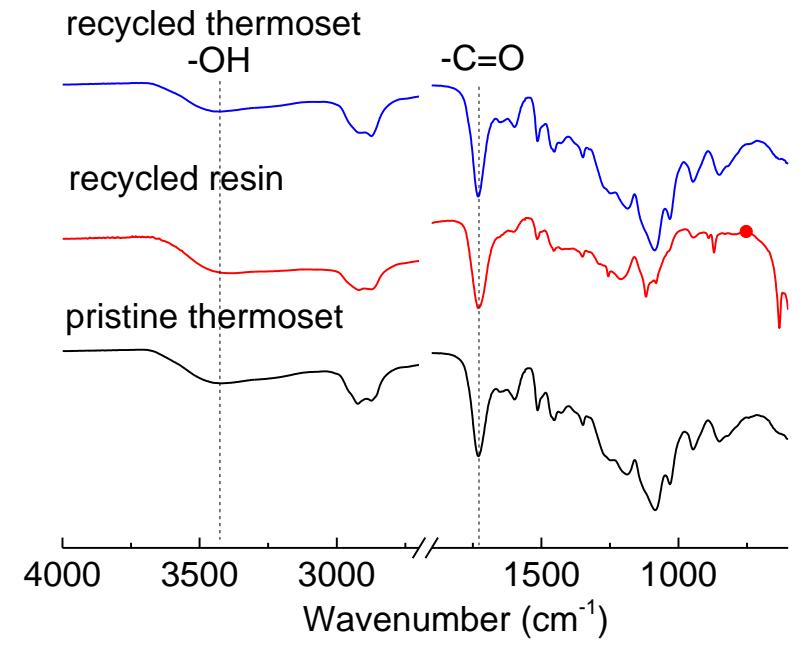

Figure S6. FTIR spectrum of pristine thermoset, recycled resin and recycled thermoset for X-

LB. 


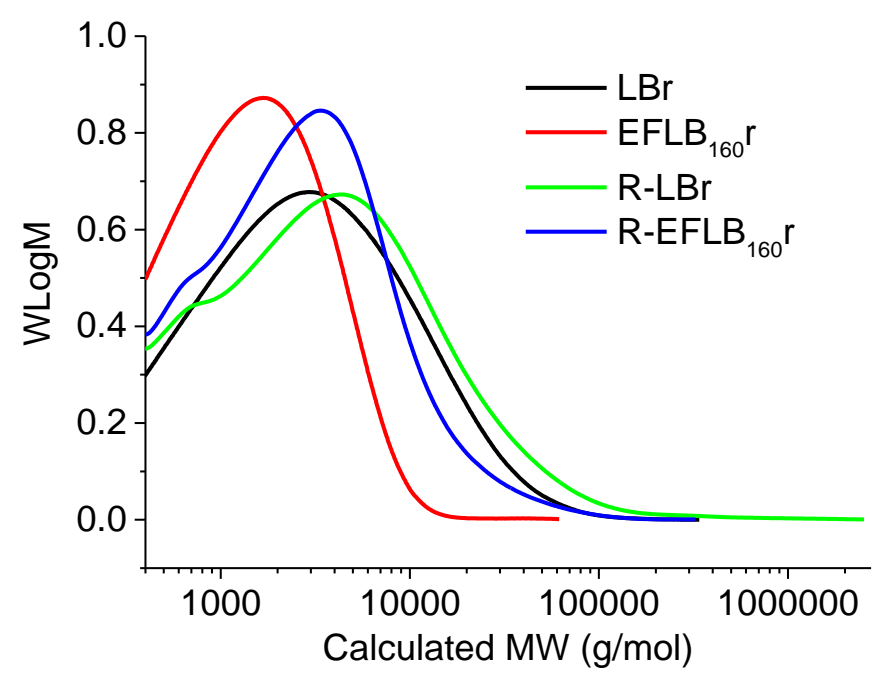

Figure S7. SEC analysis of the pristine resins $\left(\mathrm{LBr}\right.$ and $\left.\mathrm{EFLB}_{160 \mathrm{r}}\right)$ and recycled resins $(\mathrm{R}-\mathrm{LBr}$ and R-EFLB $160 \mathrm{r}$ ) for X-LB and X-LBEtOH 160.

Table S1. Number average molecular weight, weight average molecular weight and dispersity of pristine and recycled resins.

\begin{tabular}{|c|c|c|c|}
\hline Sample & $\begin{array}{c}\text { Mn } \\
(\mathrm{g} / \mathrm{mol})\end{array}$ & $\begin{array}{c}\text { Mw } \\
(\mathrm{g} / \mathrm{mol})\end{array}$ \\
\hline LBr & 1400 & 6100 & 4.4 \\
\hline EFLB $160 \mathrm{r}$ & 830 & 2000 & 2.4 \\
\hline R-LBr & 1900 & 12000 & 6.3 \\
\hline R-EFLB $160 \mathrm{r}$ & 1700 & 5200 & 3.1 \\
\hline
\end{tabular}

